\title{
The Ontogeny of Memory and Learning: Natural Intelligence versus Artificial Intelligence in Information Technology Education
}

\author{
Mahendrenath Motah \\ University of Technology, Mauritius \\ La Tour Koenig, Pointe aux Sables, Mauritius. \\ mmotah@utm.intnet.mu
}

\begin{abstract}
Over the past decades Information Technology has made a tremendous impact on the lives of humans, so much so, that one can safely state that humans eat, breathe and live IT. Each and every aspect of the life of those living in the "modern" world is under the spell of IT. The talk of the day is E-economy, E-education, E-commerce, E-finance, E-government, E-entertainment, Ecommunication, E-mail; E-learning....the world we are living in has become an E-world. In this whirlpool, many are still groping in the dark while a lot more have kept the pace in both developed and developing countries. The impact of the E thing and IT has attained such dimensions that concepts like cognition, cognitive development, fluid intelligence, crystallized intelligence, emotional intelligence, memory, learning, sensation and perception, and other related terms used to qualify, quantify and explain human experiences have become almost empty concepts in the face of what is nowadays known as artificial intelligence. This paper aims to analyse the biological, physiological and psychological aspects of memory and learning and to critically look at the impact of Information Technology Education and Information Technology in the every day dealings of humans. It also aims to be a thought provoking piece of work, to the scientific minds working on Artificial Intelligence, Robotics, Computers and derivatives, and all the perspectives that Artificial Intelligence offers to humanity, not forgetting that "the human mind and natural intelligence is behind it all”.
\end{abstract}

Keywords: ontogeny of memory; learning; intelligence and intelligences; artificial intelligence; IT education; emotional intelligence.

\section{Introduction}

The world today has, (if it has not already) become a slave to almost all of man's inventions. It all started with the discovery of the electrical energy, the power which man has been able to harness

Material published as part of this publication, either on-line or in print, is copyrighted by the Informing Science Institute. Permission to make digital or paper copy of part or all of these works for personal or classroom use is granted without fee provided that the copies are not made or distributed for profit or commercial advantage AND that copies 1) bear this notice in full and 2) give the full citation on the first page. It is permissible to abstract these works so long as credit is given. To copy in all other cases or to republish or to post on a server or to redistribute to lists requires specific permission and payment of a fee. Contact Publisher@InformingScience.org to request redistribution permission. easily for his comfort, in comparison to other energy sources like the earth (which they have entirely mortgaged), water (which is nowadays exposed to all sorts of pollution), air (which in some parts of the world has become poison), fire (which, despite all man's effort, has not been tamed yet). Man has, since the beginning of the era of inventions and discoveries, tried to become the master, but have always ended up as the slave. 
He has become a slave to all the machines he has created - so much so that if he is not careful, he can loose his own life. History has and is still a witness to man's destruction by man's own inventions.

Among the many inventions, the computer which appeared in the 1940's, initially used for numerical calculations, was soon considered as a machine which can carry out many intellectual activities. This came as the long awaited concern of many humans who were in quest of 'devices meant to mimic human behaviour, or to behave in a seemingly intelligent way" (Reingold \& Nightingale, 2005).The evolution or call it revolution that computers have brought in the field of information-processing is astounding. Among the technological advances that has marked the $20^{\text {th }}$ and $21^{\text {st }}$ century, computer science is by far the area that has known the most prolific development.

The giant strides that have been made in the field of this science since 1940 up till now have marked humanity so deeply, that human life cannot be conceived without reference to computers. The quest for building more and more intelligent programs, and to find out whether all mental activities can be carried out by computers are the order of the day. Along the way, many questions have remained unanswered, some of these are: can computers think? Do they have a language of their own? How intelligent can they be? Can they be both intelligent and creative? What about emotions and emotional intelligence? Can they possess and use human dimensions like sensory information; thought processes; emotions; consciousness; unconsciousness; common sense; can they be self-sufficient? And many more others which this paper will try to ask and perhaps propose a few answers.

Among the many challenges that the field of computer science has brought to humanity, the one that we wish to propose is the confrontation between natural intelligence and the concept of "artificial intelligence" reputed to have been coined in 1956 by American scientist John McCarthy (Shinghal, 1992). We will start by defining natural intelligence then proceed to some further discussions on memory, learning, intelligence and other related themes, to end with the importance of these concepts in the field of Information Technology Education.

\section{Ontogeny of Memory}

Memory is the retention over time, and comprises the following stages: Encoding- how information gets into memory; Storage - retention of information over time; Retrieval - when information is taken out of storage, (Santrock, 2000). Memory is the web of private images in which past and present are interwoven. It is unique for each and every individual.

Experiments carried out with both humans and animals have shown that memory is an important determinant of behaviour. Memory helps individuals to attend to information, how they perceive it, how they store it, how they think about it, and how they retrieve it for further use (Santrock, 2000). Various aspects of memory have been revealed through research: how memory systems operate (Schacter,1996, 1999); levels of processing theory (Craik \& Lockhart, 1972) states that memory is on a continuum from shallow to deep, with deeper processing producing better memory; rehearsal - the conscious repetition of information that increases the length of time that information stays in memory (Santrock, 2000); elaboration - extensiveness of processing at any given depth in memory, (Craig \& Tulving, 1975); imagery - memory is stored either as a verbal code or as an image code, (Paivio, 1971, 1986; Shepard, 1996); organization - remembering becomes easier if we can organize information hierarchically (Bruning, Schraw, \& Ronning, 1999).

Further studies on how the memory functions have helped the formulation of certain theories which are still being discussed. Among these, the Atkinson-Shiffrin Theory which states that memory involves a sequence of three stages: sensory memory, short-term memory and long term memory. Sensory memory deals with the sights iconic memory, and sounds echoic memory. 
Other dimensions underlined by the Canadian psychologist Endel Tulving (1972) are the Episodic memory which is the retention of information about the where and the when of life's happenings; and the Semantic memory which is a person's knowledge about the world.

Further, two other theories which have contributed to a better understanding of memory are: The Schema theory of memory (Bartlett, 1932) studied how people remember stories; (a schema being a concept or framework that already exists in the person's mind and that organizes and interprets information). The Network Theories which stressed that, memories consist of complex nodes that are hierarchically arranged.

There seem to be much confusion in the theories on the location of memory in the brain. Several scientists have expressed their views on the question. Haberlandt, (1999) enquires about the brain's role in the retention of memory; Karl Lashley (1950) spent his lifetime looking for a location where memories are stored in the brain; Larry Squire (1990) states that most memories are probably clustered in groups of about 1,000 neurons, and points out that memory is distributed throughout the brain, no memory centre exists. Lynch (1990) states that memory is localized in the sense that a limited number of brain systems and pathways are involved, and each probably contributes in different ways.

An important element which has helped cognitive neuroscience research is the role of the brain in remembering and forgetting experiences (Neergaard, 1998). Scientists are involved in studying how people encode their experiences in their brain and how far the brain is involved in this encoding.

These have also enlightened scientists on memory retrieval and forgetting and at the same time helped to understand related concepts like: tip-of-the-tongue phenomenon; serial position effect; the primacy effect and the recency effect; and other factors involved in retrieval of information from memory which are recall and recognition; and the important aspect of forgetting (Ebbinghaus 1850-1909).

Human brain and memory possess so many features which are yet to be investigated, understood and mastered that computers are far behind in many aspects. We still have to deal with autobiographical memory (Conway \& Rubin, 1993; Schacter, 1996); emotional memories: flashbulb memories (Rubin \& Kozin, 1984); personal trauma (Langer, 1991; Schacter, 1996); repressed memories; mood-congruent memory, (Mineka \& Nugent, 1995).

As pointed out by Alice O'Toole, University of Texas- "How the brain organizes and interprets sensory information to give it meaning is a little miracle that scientists are still trying to solve”.

The various aspects that could be described, explained and discussed are so numerous that it would be too tedious and lengthy for this short paper to delve deeper into them. But, it is hoped that the aspects highlighted in this part will enable readers to understand how much has yet to be done before we can let ourselves be guided by machines.

\section{Learning}

We do not want to extend over the concept of learning going through Classical Conditioning, Pavlovian Conditioning, and Operant Conditioning (Skinner, 1938). As cognitive processes have assumed a more important role in learning, (Santrock, 2000), we are going to emphasise on Observational learning (Bandura, 1986, 1994) described as the capacity to learn behaviour patterns by observation and comprising of the four main processes of attention, retention, motor reproduction and reinforcement.

Attention is directly influenced by sensation (the process of detecting and encoding stimulus energy: light, sound, heat in the world, and perception (the brain's process of organizing and in- 
terpreting sensory information to give it meaning). The two processes of sensation and perception are virtually inseparable. They are considered as a unified information-processing system (Goldstein, 1999).

The second process is retention - to be able to reproduce any information, one must code the information and keep it in memory so that it can be retrieved. To be able to reproduce any behaviour (motor reproduction) one needs to attend to what is perceived as important and code it in memory so that it can be retrieved and reproduced.

The final process involves reinforcement, or incentive conditions, whereby the organism is encouraged to indulge in the desirable behaviour, or should completely discard the said behaviour from the usual existing behaviour pattern (Bandura, 1965).

To proceed a little further in the field of learning, we cannot minimize the role of cognitive factors - cognitive maps: an organism's mental representation of the structure of physical space as proposed by E.C.Tolman, (1948); insight learning: form of problem solving in which the organism develops a sudden insight or understanding of a problem's solution (Kohler, 1925).

The other set of factors which influence learning are: the biological factors, which permit certain kinds of learning and inhibit others (Chance, 1999), preparedness- the organism's predisposition to learn in certain ways but not others (Seligman, 1909); and cultural factors, for, the content of learning is also influenced by culture (Cole \& Cole, 1996); learning requires practice, and certain behaviours are practiced much more often in some cultures than others.

Most, if not all the characteristics and features highlighted above are proper to humans, machines can only imitate what humans do, they can only do whatever they are programmed for, no more no less.

Although machines like the computers have memory and can "learn", yet they can only use what humans have placed in" their memory ", and they can do only what they are "taught" - computers cannot learn to learn as humans can.

No two people learn the same way. Each of us has his/her own way to learn and adopts different learning styles: convergers, divergers, assimilators or accommodators (Lussier, 1990).

These lead to believe that each one of us, though being alike, is different and possess a memory that is unique, experiences that are unique, is genetically different and learn things according to certain predispositions. These make us all humans, but at the same time different, with characteristics and temperaments which create and confirm important individual differences.

\section{Intelligence and Intelligences}

As humans, our life is determined and influenced by various dimensions: a biological inheritance and physical appearance that distinguish us from other living beings; a psychological make-up which determines our mental, emotional, linguistic, behavioural and moral aspects; a social need which affects all aspects of our existence and lifestyle; and a spiritual dimension which helps us to distinguish right and wrong.

The most important and most prized possessions is intelligence, yet it is a concept that even the most intelligent people ha not been able to agree on (Santrock, 2000). The same author has defined intelligence 'as verbal ability, problem-solving skills, and the ability to learn from life's everyday experiences”.

Various theories have been propounded by psychologists during the past decades: Charles Spearman's (1927) two factor theory stated that individuals have both general intelligence which he called $g$, and a number of specific intelligences which he called $s$. 
L.L.Thurstone's (1938) Multiple-factor theory stated that intelligence consists of seven primary mental abilities: verbal comprehension, number ability, word fluency, spatial visualization, associative memory, reasoning and perceptual speed.

Contemporary approaches to intelligence proposed by Howard Gardner $(1983,1993)$ from Harvard University and Robert. J.Sternberg $(1997,1999)$ emphasizes the multiple intellectual abilities humans possess.

H. Gardner's Seven Frames of Mind, includes seven components which he identified as: verbal thinking, logical/mathematical thinking, spatial skills, movement skills, musical skills, insightful skills for self-understanding and insightful skills for understanding others.

On his part, J. Sternberg states that "My view of intelligence is quite different from the conventional one. Successful intelligence, as I view it, involves analytical, creative and practical aspects”. His Triarchic theory consists of: componential intelligence - (basic unit of information processing- acquisition, retention, retrieval, transfer of information for decision-making and problem-solving); experiential intelligence (experiences, learning, insight, creativity); contextual intelligence - (getting along in the real world).

Despite attempts made by various researchers to reach a consensus on the definition of the concept of intelligence we have witnessed both converging and diverging views.

The absence of a real consensus has given rise to controversies, and these have resulted in creating difficulties to understand the nature of intelligence.

Some of the controversies are closely related to the nature of humans and lead us to get into the age-old nature/nurture controversy; to the role of ethnic and cultural factors in intelligence; and the measure of intelligence, if ever it could be measured objectively.

\section{Artificial Intelligence}

The concept of "Artificial Intelligence” was introduced by John McCarthy in the summer of 1956, when he organized 'the Dartmouth summer research project on Artificial Intelligence” (Reingold \& Nightingale, 2005).

In the 1940's the development of computer science aimed at providing logistic support through numerical calculations to belligerent countries during the war. The first modern computer, was developed by John von Neumann in the late 1940s, showed that inanimate machines could perform logical operations (Santrock, 2000)

In the 1950's British mathematician and computer scientist Alan Turing published an important article entitled "Computing machinery and intelligence", in which he introduced what was known as the "Turing test"; ideas about a thinking machine were analyzed and rejected, and the possibility of a "thinking" computer was discussed.

Exploration in the field of computers led to attempts to build intelligent computer systems; which opened new pathways and saw the emergence of Artificial Intelligence: "the science of creating machines capable of performing activities that require intelligence when they are done by people”. Artificial intelligence is helpful in tasks requiring speed, persistence, and a vast memory, (Hancock, 1999); and are systems which attempt to mimic the way humans think (Dawson, 1998; Ellis \& Humphreys, 1999). Here it would be important to underline that thinking "involves mentally manipulating information, as and when we form concepts, solve problems, reason, and make decisions”. Are computers capable of doing any of these mental activities?

For the above reasons and other arguments which have been raised by Alan Turing (1951) "The imitation Game”; in which he argued that if the machine could successfully pretend to be human 
to a knowledgeable observer then you certainly should consider it intelligent. Whereas philosopher John Searle argued that just behaving intelligently was not enough. He tried to demonstrate this by suggesting a thought experiment "The Chinese Room" and said that the idea of a nonbiological machine being intelligent is incoherent. Other researchers concluded that if artificial intelligence has not reached human level by now, it must be impossible.

Artificial intelligence research makes the assumption that human intelligence can be reduced to the manipulation of symbols, and that it does not matter what medium is used to manipulate these symbols, it does not have to be a biological brain (Cawsey, 1994).

Conclusions drawn from the readings from the 1940's through to the 1980's and the 1990's till today, clearly indicate that artificial intelligence will always remain as it is "artificial"- computers can never achieve true intelligence, they will always need human inputs. They can be programmed to be intelligent, but will never be able to use that intelligence to program themselves; they will always need human's natural intelligence.

\section{Information Processing: Brain v/s Computer.}

Cognitive psychologists often use the computer as an analogy to help explain the relation between cognition and the brain (Kirlick \& Bisantz, 1999). The physical brain is described as the computer's hardware, cognition as its software. But, it is generally agreed that inanimate computers and human brain function quite differently in some respects (Restak, 1988).

The human Nervous System (NS) which is the body's electrochemical communication circuitry is made up of billions of neurons. The NS is divided into two parts: The Central Nervous System (CNS), made up of the brain and spinal cord. The other part is The Peripheral Nervous System, the network of nerves that connect the brain and the spinal cord to the other parts of the body. This part has two major divisions, the somatic nervous system consisting of sensory nerves, which convey information from the skin and muscles to the CNS about such matters as pain and temperature, and motor nerves, which inform muscles when to act. The autonomic nervous system takes messages to and from the body's internal organs, monitoring such processes as breathing, heart rate and digestion. This part is also divided into two parts, the sympathetic nervous system, the division that arouses the body, and the parasympathetic nervous system, the division that calms down the body.

The neurons or nerve cells are the NS's basic units. Highly organized, the nervous system is continually at work processing information about everything we do (Colan et Al, 1999).Information flows into the brain, within the brain and out of the brain along specialized neurons known as afferent nerves, sensory nerves that carry information to the brain; efferent nerves, or motor nerves, carry the brain's output. The interneurons are in turn involved in a more complex information processing; they are the CNS neurons that mediate sensory input and motor input.

Human brain is estimated to have something of the order of ten to a hundred billion neurons. Each brain cell or neuron is alive and can be altered in its functioning by many types of events in its biological environment. The brain controls all our thoughts and movements. The brain's neural network is a complex system within the brain structure which is made up of the hindbrain, the midbrain, and the forebrain. Each of these is perfectly structured and consists of various elements, responsible for all the behaviours, both overt and covert in humans.

About 99 percent of all the neurons are located in the Central Nervous System. The neurons, connected in precise ways through synapses and neurotransmitters, compose the various structures of the brain (Smock, 1999) and form the natural neural network.

The science that studies the brain and the nervous system: neuroscience, has contributed to the understanding of the connection strengths between neurons; how one neuron influences other 
neurons connected to it; and how information is transmitted through them to the various parts of the body; how the brain really functions (Reingold \& Nightingale, 2005)

Equipped as it is, the brain derives information about the world through a rich and complex system of visual, auditory, olfactory, gustatory, tactile, and vestibular sensory receptors. The human brain also has the incredible ability to learn new rules, relationships, concepts, and patterns that it can generalize to novel situations.

The structure and function of the human brain is as complex as seen from the above analysis. It becomes even more complicated to explain if we add to these, the limbic system, the thalamus, the hypothalamus, the neocortex, the cerebral hemispheres; the brain and the endocrine system and other related neuroscience concepts

A few questions arise when we compare the human brain to computers. Can computers be really intelligent? They can perhaps do intelligent things, can the really think as our brain does? Are they capable of being creative - propose novel solutions to problems, or see things from different angles? Let alone intelligence, can they deal with things using emotions? Do they possess emotional intelligence?

Efforts and attempts to simulate the brain, and to create artificial neural networks have been at the basis of the creation of artificial intelligence. Researchers believe that certain key properties of the brain cells can be extracted and applied to simulations, thus creating a simulated simplified brain (Reingold \& Nightingale, 2005).

The approach seems to be a reductionism of the functions of a neuron. Using the knowledge of the brain structure and the natural neural network, computer scientists are focusing their effort on understanding the connection strength of neurons, the inhibition/excitation characteristics of neurons, and the transfer function of neurons in information processing in order to create an artificial neural network...

Once understood and mastered, the knowledge could be used to create neural nets capable of thinking, discrimination, and learning, in short be intelligent enough to simulate the human brain in its simplest and maybe its most primitive form...

According to E. Reingold \& J. Nightingale, (2005), "the most significant difference between artificial and biological neural nets is their organization. While many types of neural nets exist, most are organized according to a same basic structure made of three components: a set of input nodes, one or more layers of hidden nodes and a set of output nodes. The input nodes take in information, and are akin to sensory organs - ....”

I think that the comparison stops somewhere here, as the information supplied has nothing in common with the sensory information that a biological neural net receives for processing. The artificial neural net receives coded information in the form of "digitized picture" or a "series of figures" or any other form that can be "numerically expressed".

The human brain receives sensory information in the form of visual stimulus through the eye; sounds and sound waves that are processed by the auditory (hearing) system; the skin senses consisting of the senses of touch; temperature and pain provide the brain with yet another set of information. The chemical senses consists of taste and smell, which are other types of information that only the human brain and body can process. Last, we have the kinesthetic and vestibular senses; the kinesthetic senses provide information about movement, posture, and orientation, while the vestibular sense provides information about balance and movement (Santrock, 2000). 


\section{Future of IT Education and Artificial Intelligence.}

Human intelligence is a complex and slippery concept which has and is still creating major controversies. The field of IT the major one to affect it and affected by it, because IT has conquered almost every aspect of human life.

Human intelligence involves both "mundane” and "expert” reasoning (Cawsey, 1994). According to the author, the mundane aspect applies to all those activities which all of us can routinely do depending on our abilities, in order to act and interact in the world, and would include:

- Vision - the ability to make sense of what we see.

- $\quad$ Natural Language - the ability to communicate with others.

- Planning - the ability to decide on a good sequence of actions to achieve goals.

- Robotics - the ability to move and act in the world, possibly responding to new perceptions.

The expert reasoning would refer to things that only some people are good at, and which require extensive training. These would include:

- Medical diagnosis.

- $\quad$ Equipment repair

- Computer configuration

- Financial planning.

Expert systems are concerned with the automation of these sorts of tasks. In the face of difficulties in creating general purpose intelligent machines, an alternative approach developed which attempted to mimic human performance within restricted domains of knowledge (Reingold \& Nightingale, 2005) and produce Artificial Intelligence.

The authors state that the first serious attempt at applying this alternate approach came to be known as 'Microworlds".

The theory behind Microworlds was as follows:

- Step 1 - AI producing intelligence in a restricted environment.

- $\quad$ Step 2 - gradually increase the complexity of the environment, and the AI.

- $\quad$ Step 3 - AI reaches a level that could cope with real-world situations.

Application of the theory proved to be difficult, but showed that AI systems designed to operate within domains of knowledge that are narrow, but deep, could be highly effective.

This realization inspired the creation of one of the most successful areas of AI - the field of expert systems. The basic idea is that if one can codify human expertise within a narrow domain as a hierarchical series of if-then rules, then an AI system can be created that mimics or perhaps even exceeds the performance of a human expert. Deeper incursion in the domain to reconcile expert systems and human experts possessing relevant knowledge saw the emergence of what is known as "Knowledge Engineer". Persons occupying this position spend time with human experts during the design stage of an expert system, as well as during multiple feedback and improvement cycles. (Reingold \& Nightingale, 2005).

AI research has made a few successful strides in the area of expert reasoning, but the mundane tasks have, till now proved to be the hardest to automate, (Cawsey, 1994), perhaps because they are more natural intelligence-based, and are proper to living organisms than anything else. 


\section{Word of Caution}

As pointed out in the introductory part, we are living in an E- World living an E-life. We often believe that with our portable computer, phone, diary, and other E-gadgets, we are independent.

The solitary bird in his/her electronic cottage believes he/she is better off than to be with colleagues working in offices.

We should once in a while stop and think of the social cost we are enduring for what many of us consider as evolution and progress.

Is artificial intelligence better than natural intelligence? Is the virtual world better than the real world? Is the electronic cottage better than the real office? Is........

\section{Conclusion}

As concluding remarks we would like to quote the following from John McCarthy (2004). "Computer programs have plenty of speed and memory but their abilities correspond to the intellectual mechanisms that program designers understand well enough to put in programs. Some abilities that children normally don't develop till they are teenagers may be in, and some abilities possessed by two years old are still out. The matter is further complicated by the fact that the cognitive sciences still have not succeeded in determining exactly what human abilities are. Very likely the organization of the intellectual mechanisms for AI can usefully be different from that in people.

Whenever people do better than computers on some task or computers use a lot of computation to do as well as people, this demonstrate that the program designers lack understanding of the intellectual mechanisms required to do the task efficiently”.

The views expressed in this short comparison between human and computer intelligence summarizes perfectly the ideas behind the presentation of the paper.

\section{References}

Bandura A. (1977). Social learning theory. Prentice-Hall.

Beatty J. (1995). Neuroscience. NY: McGraw- Hill.

Bartlett J. (1932). Remembering. Cambridge University Press.

Bruning, RH, Schraw, G.J. \& Ronning, R.R. (1999). Cognitive psychology and instruction (3rd ed.). NJ.

Cawsey A. (1994). What is artificial intelligence? BST.

Chance, P (1999). Learning and behaviour (4th ed.). Belmont, CA: Wadsworth.

Cole \& Cole (1996). The development of children (3rd ed.). NY, Freeman.

Coleman, D (1994). Emotional intelligence. Bantam Books.

Colan, et al. (1999). States of the mind. NY: Wiley.

Craik, F.I.M, \& Lockhart, R.S (1972). Levels of processing: A framework for memory research. Journal of Verbal Learning and Verbal Behavior, 11, 671-684.

Craik, F.I.M, \& Tulving, E (1975). Depth of processing and retention of words in episodic memory. Journal of Experimental Psychology: General, 104, 268-294.

Conway, M. A. \& Rubin, D.C. (1993). The structure of autobiographic memory. In A. F. Collins, S. E. Gathercole, M. A. Conway, \& P. E. Morris (Eds.), Theories of memory (pp. 103-137). Lawrence Erlbaum, Hove. 
Dawson, M.R.W. (1998). Understanding cognitive science. Malden, MA Blackwell.

Ellis, R. \& Humphreys, G.W. (1999). Connectionist psychology. Philadelphia: Psychology Press.

Gardner, H. (1993). Frames of mind. NY: Basic Books.

Gardner, H. (1993). Multiple intelligence. NY: Basic Books.

Goldstein, E.B. (1999). Sensation and perception (5th ed.). CA: Brooks/Cole.

Haberlandt, K. (1999). Human memory. Boston: Allyn \&Bacon.

Hancock, P.A. (1999). Human performance and ergonomics. San Diego: Academic Press.

Kirlik, A., \& Bisantz, A.M (1999). Cognition in human-machine system. San Diego: Academic Press.

Kohler, W, (1925).The mentality of apes. NY.

Langer, L.L. (1991). Holocaust testimonies: The ruins of memory. Yale University Press.

Lashley, K. (1950). In search of the anagram. NY, Cambridge University Press.

Lussier, R.N. (1990). Human Relations in Organisations. Irwin.

Lynch, G. (1990). The many shapes of memory and the several forms of synaptic plasticity. Dallas.

Mineka, S. \& Nugent, K (1995). Memory distortions: How minds, brains and societies reconstruct the past. Cambridge. MA: Harvard University Press.

Neergaard, L. (1998). Scientists get insight on memory by watching brain activity.

O’Rahilly, R., \& Muller, F. (1999). The embryonic human brain. NY: Wiley.

Paivio, A. (1971). Imagery and verbal process. NY: Holt, Rinehart \& Winston.

Paivio, A. (1986). Mental representations: A dual coding approach. NY: Oxford University Press.

Rubin, D.C. \& Kozin, M, (1984). Vivid memories. Cognition, 16, 81-95.

Restak, R.M. (1988). The mind. NY: Bantam.

Reingold, E \& Nightingale, J (2005). Artificial Intelligence Tutorial Review. Available at http://www.psych.utoronto.ca/ reingold/courses/ai/ai.html

Santrock, J.W (2000). Psychology (6th ed.). McGraw-Hill.

Schacter, D.L. (1996). Searching for memory. NY: Basic Books.

Schacter, D.L. (1999). Consciousness in the new cognitive neurosciences (2nd ed.). Cambridge, MA; MIT Press.

Seligman, M.E.P. (1990). Learned optimism. NY: Knopf.

Shepard, R.N. (1996). The eye's mind and the mind's eye. Paper- Toronto.

Shinghal R. (1992).Formal concepts in artificial intelligence. Chapman \&Hall.

Skinner, B.F. (1938). The behaviour of organisms: An experimental analysis. NY: Appleton-CenturyCrofts.

Smock, T.K. (1999). Physiological psychology: A neuroscience approach. .NJ: Prentice-Hall.

Spearman, C.E. (1927). The abilities of man. NY: Macmillan.

Sternberg, R.J. (1997). Successful intelligence. NY: Simon \&Schuster.

Sternberg, R.J. (1999). Intelligence in encyclopedia of creativity. San Diego: Academic Press.

Thurstone L.L. (1938). Primary mental abilities. Chicago: University of Chicago Press.

Tolman, E.C. (1948). Cognitive maps in rats and men. Psychological Review. 
Tulving, E. (1972). Episodic and semantic memory. In Origins of memory. San Diego: Academic Press.

\section{Biography}

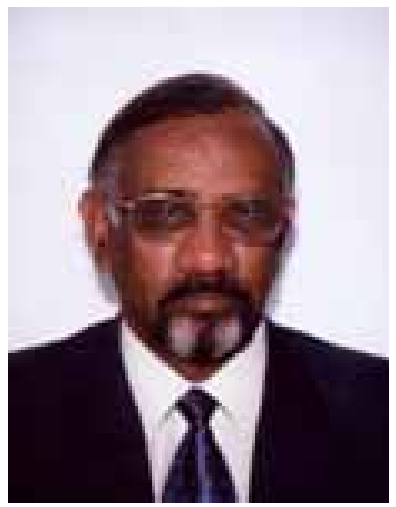

Mahendrenath MOTAH is Senior Lecturer at the University of Technology, Mauritius. He has a Postgraduate Diploma in Educational Psychology from Paris V, Rene Descartes, University; Master's Degrees in Psychology and Ethnology, and a PhD in Arts and Human Sciences from Paris VII, Jussieu University, Paris, France. He has spent three months as a Visitor at Jordanhill College of Education, Glasgow, Scotland in April- July1985 under the British Council. He has spent one month in USA, as a Visitor under USIA in June 1987. He also attended the Laurentian University, Sudbury, CANADA in connection with the Distance Education Links Project, under CIDA in June 1995. He has participated in various Workshops, Seminars and Conferences at National and International levels. He has extensive experience in the fields of Management, Administration and Training at both National and International levels. He has been Training Manager for an International Hotels and Resorts Company from 1996 - 1998. He has also been Advisor in Psychological Matters for the Ministry of Youth and Sports during the period 1999 - 2000 before joining the University of Technology, Mauritius in April 2000. He is Chairperson of the Regional Centre for Urgent Anthropological and Ethnological Research. His interests are research in the field of education and human sciences. He is at present working on a Master's programme in Educational Administration and Technology.

He presented a paper on “Accommodating Soft Skills in Software Project Management”, in Flagstaff, Arizona, USA, during the Informing Science + Information Technology Education Joint Conference: $16^{\text {th }}-19^{\text {th }}$ June, 2005. He has also presented a paper on "The need for a consensual, coherent and comprehensive approach to tourism education in developing countries, with reference to some Indian Ocean Islands” at the Recent Developments in Tourism Research Conference held at the Algarve University, Faro, in Portugal, on 6-8 October 2005. 